\title{
Anthropometry of the proximal femur and femoral head in children/ adolescents using three-dimensional computed tomography-based measurements
}

\author{
Ali Darwich ${ }^{1}$. Christiane Geiselhardt ${ }^{1} \cdot$ Mohamad Bdeir $^{1} \cdot$ Sonja Janssen ${ }^{2} \cdot$ Stefan O. Schoenberg ${ }^{2}$. \\ Sascha Gravius ${ }^{1} \cdot$ Ahmed Jawhar $^{1,3}$
}

Received: 18 January 2021 / Accepted: 19 September 2021 / Published online: 1 October 2021

(C) The Author(s) 2021

\begin{abstract}
Purpose Defining normal anthropometric ranges of proximal femur and femoral head for each age group in children/adolescents is a necessity when differentiating normal anatomical variants from pathological deformities. Aim of this study is to define a set of normal anthropometric parameters based on 3D-CT measurements in normal asymptomatic children/ adolescents and analyse the variations arising depending on age, side, and/or gender.

Methods Morphology of the proximal femur was retrospectively assessed in 170 hips ( 85 children, $<15$ years). Measurements included covered femoral head volume (CFHV), femoral head diameter (FHD), femoral head extrusion index (FHEI), coronal alpha angle (CAA), lateral centre-edge angle (LCEA), anterior (AOS) and posterior head-neck offset (POS) and femoral neck-shaft angle (FNSA). Correlation analyses as well as inter- and intra-rater reliability were performed.

Results CFHV, LCEA, FHD and AOS/POS increased with age and FHEI, CAA, and FNSA decreased with age. None of the measurements correlated with the side. AOS showed a poor correlation with gender. Rapid growth phases were observed at the age of 1,7 and 11 . The inter- and intra-rater reliability was high (range ICC 0.8-0.99 Cronbach alpha 0.86-0.99).

Conclusion This data delivers a description of growth phases as well as gender and age-correlated reference values of the proximal femoral morphology that could be used by paediatricians and orthopaedic/paediatric surgeons to early diagnose proximal femur deformities and provide guidance in the planning of possible operations.
\end{abstract}

Keywords Anthropometry $\cdot 3 \mathrm{D}$ computed tomography $\cdot$ Measurements $\cdot$ Proximal femur $\cdot$ Children

Ahmed Jawhar

ahmed.jawhar@medma.uni-heidelberg.de;

ahmed.jawhar@klinikum-worms.de

Ali Darwich

alidarwich@mail.com

Christiane Geiselhardt

christiane.geiselhardt@gmail.com

Mohamad Bdeir

mohamad.bdeir@umm.de

Sonja Janssen

sonja.janssen@medma.uni-heidelberg.de

Stefan O. Schoenberg

stefan.schoenberg@umm.de

Sascha Gravius

sascha.gravius@umm.de
1 Department of Orthopaedics and Traumatology Surgery, University Medical Centre Mannheim, Medical Faculty Mannheim, Heidelberg University, Theodor-Kutzer-Ufer 1-3, 68167 Mannheim, Germany

2 Clinic of Radiology and Nuclear Medicine, University Medical Centre Mannheim, Medical Faculty Mannheim, Heidelberg University, Theodor-Kutzer-Ufer 1-3, 68167 Mannheim, Germany

3 Department of Trauma, Orthopedics, Hand and Reconstructive Surgery, Klinikum Worms, Academic Teaching Hospital of the University Mainz, Gabriel-von-Seidl-Straße 81, 67550 Worms, Germany 


\section{Introduction}

The hip joint is considered as a ball-and-socket joint between the acetabulum and the proximal femur and femoral head facilitating load transmission to the lower limbs. It is the second largest load-bearing joint in the body, following the knee joint [1].

The hip may show a large array of morphological variations, especially with increasing age or depending on gender. These variations can sometimes be excessive and pathological leading to a painful unproportionate load distribution in the joint causing eventually pathological wear of the joint cartilage, thus being defined as biomechanical risk factors for osteoarthritis [3]. The most prevalent pre-arthrotic condition is by far hip dysplasia, which represents a typical altered distribution of load causing focal cartilage damage [16]. Children with developmental dysplasia of the hip (DDH) present not only with acetabular malformation and hypoplasia, but also with deformations of the proximal femur and femoral head. This condition, when left untreated, results in most cases in a rapidly progressing osteoarthritis, as early as in young adulthood or late adolescence, where a 4.3 -fold increase in the rate of radiographic hip osteoarthritis is seen [24]. The untreated DDH is the most common cause of hip arthroplasty in young adulthood [17]. Beside genetic predisposition, DDH is the end result of a combination of intrinsic and extrinsic mechanical factors. Alongside a combination of morphological anomalies of the acetabulum regarding inclination, orientation, volume and size, DDH encompasses a series of malformations of the proximal femur and femoral head as well, consisting of insufficient femoral head coverage, abnormal version and excessive angulation from femoral shaft [17]. Dysplasia is solely an example of the numerous pathologies involving the proximal femoral morphology and that of the femoral head and causing devastating consequences in young adulthood or late adolescence, thus proving that the geometry of the proximal femur plays a fundamental role in the existence and progress of these conditions [4].

In order to detect such abnormalities, normal ranges of morphometric parameters of these structures have to be previously defined [5]. The anthropometry of the adult hip has already been described [35]. In children however, such studies hardly exist, and when they do, they are based on plain X-rays or two-dimensional computed tomography (2D CT), that do not necessarily reflect the most precise measurement method [25]. These methods show many limitations especially in cases where the position of the patient during imaging varies, in pelvic inclination or rotation for example [38]. Consequently, as recommended by many authors [19] and in order to deliver the most precise measurements, three-dimensional computed tomography (3D-CT)-based techniques were adopted in this study as cross-sectional imaging technique for more precise measurements without overlapping and true of scale.

Aim of this study was to provide standardized reference values at a broad age range - to the best of our knowledge unprecedented in the literature so far-concerning the anthropometric morphological development of the of the proximal femur and femoral head based on 3D-CT techniques in asymptomatic children/adolescents and highlight any deviations regarding side and gender.

\section{Material and methods}

\section{Study population}

In this retrospective study, an anonymized data base was used to measure the linear and volumetric dimensions of the proximal femur and femoral head in asymptomatic children $<15$ years of age.

Analysed age groups were categorized according to the year of birth: the first year of life (from birth till 12 months of age) was referred to as group 0, children aged 13-24 months were categorized as group 1, children aged 25-36 months were categorized as group 2 etc.

Patients $>15$ years or patients presenting with hip symptoms were excluded. Further exclusion criteria included tumours in the hip region, Perthes disease, slipped capital femoral epiphysis, destructive arthritis of the hip, hip dysplasia, hip deformity and previous hip surgery or hip trauma. All performed scans were clinically indicated and were done for non-hip-related reasons: 52/85 (61\%) were trauma related scans and 33/85 (39\%) were done on patients with abdominal symptoms. None of the CTs was done for the sole purpose of the study.

Prior to the performance of the measurements, all CT exams were read by a board-certified radiologist (SJ) and a board-certified orthopaedic surgeon (AD) in consensus evaluation to exclude any hip deformity or trauma and confirm the eligibility of the patients to be included in the normative collective. All included CT exams were then read by two orthopaedic surgeons (AD and AJ) with 10 and 7 years of experience in the hip region blinded to each other's measurements.

\section{CT Data acquisition and reconstruction planes}

All analysed scans included the pelvis and both proximal femurs and were performed between 09/2008 and 09/2019 on different CT scanner systems within our institution $(2 \times 192$ slice dual-source CT, $2 \times 128$ slice dual-source CT, 16-slice single-source CT). Using a helical technique with 
pitch factors from 0.55 to 3 and collimations of $0.6 \mathrm{~mm}$ or $1.2 \mathrm{~mm}$, imaging was done in a standard supine position. Before performing the study measurements all datasets were uniformly reoriented and reconstructed in parallel and orthogonal planes to the pelvic anatomical plane in order to standardize the measurements between the scans, regardless of the default reconstruction within the Picture Archiving and Communication System (PACS) and regardless of the patient's positioning during data acquisition.

Volume CT dose index (CTDIvol) ranged from 0.18 to $74.89 \mathrm{mGy}$. The broad range is due to the fact that indications for CT were highly variable in the retrospective collective analyzed and so was the scan range along the $z$-axis. Slice thickness was $\leq 1.5 \mathrm{~mm}$ with an increment equal or smaller than the slice thickness.

All measurements were carried out on the the aycan ${ }^{\circledR}$ workstation OsiriX (aycan Medical Systems ${ }^{\circledR}$, Rochester, NY, USA). A detailed list of the performed measurements is to be found in Table 1.

\section{Measurements}

The first author (AD) performed all measurements twice at a minimum interval of two months. The final values presented in the current study and all further analysis was based on the mean values of these two readings. The same measurements were performed by the senior author (AJ) independently. Both observers were blinded to each other's results. Both observers performed the measurement according to a welldefined plane configuration set a priori (Table 1). The two readings of the first observer were compared to assess the intrarater reliability. The readings of the first and the second observer were compared to evaluate the interrater reliability.

The performed measurements included covered femoral head volume (CFHV), femoral head diameter (FHD), femoral head extrusion index (FHEI), coronal alpha angle (CAA), lateral centre-edge angle (LCEA), anterior (AOS) and posterior head-neck offset (POS) and femoral neck-shaft angle (FNSA). Selection of the measurements was done according to their clinical relevance. The femoral head extrusion index and the lateral centre-edge angle estimate the weight-bearing surface of the hip [15]. On the other hand, the femoral neck-shaft angle is used to evaluate the morphology of the proximal femur. These measurements are some of the classical parameters used not only to detect hip deformity but also to plan complex three-dimensional osteotomies of the pelvis [30].

\section{Statistical analysis}

Mean values and standard deviations (SD) were used to describe quantitative morphometric parameters. Because of the high number of performed correlations (see Table 3) the Bonferroni method was used to correct increased error rates, and the statistical significance was indicated by a $p$ value of $<0.00017 .95 \%$ double-sided confidence intervals (CI) were calculated. Student's $t$ test was used to analyze parametric data and Wilcoxon rank sum-test to analyze nonparametric data. Pearson coefficients $(r)$ were used to assess bivariate correlations to age, gender, and side. Cronbach`s alpha $(\alpha)$ was used to evaluate internal consistency (see Table 2). Intraclass correlation coefficients (ICCs) were used to perform inter- and intra-rater reliability analyses for two of the authors independently at different time points, with at least 14 days between the two measurements (see Table 2).

A repeated ANOVA (procedure Proc Mixed) was used to assess the distribution of cases inside each age group by evaluating the number of available cases per month of birth in each year. Taking case dispersion in each age group into consideration, growth phases were presented using sextic polynomial curves.

GraphPad Prism 8 (Version 8.4.2, San Diego, CA, USA) was used to create graphs. Statistical analyses were performed using SPSS (Version 9, IBM, Chicago, IL, USA).

\section{Ethics approval}

This study was approved by the Ethics Committee of clinical research at our institution (Ethics Committee II, University Medical Centre Mannheim, Medical Faculty Mannheim, Heidelberg University, Theodor-Kutzer-Ufer 1-3, 68167, Mannheim, Approval 2016-870R-MA) and performed in accordance with the local ethical standards and the principles of the 1964 Helsinki Declaration and its later amendments.

\section{Results}

The series consisted of 170 hips (85 patients, 46 males and 39 females), with a median age of $6 \pm 5$ years (males $6 \pm 5$ years and females $8 \pm 5$ years) (range $0-15$ ). In total, 16 groups were formed (age range $0-15$ ) with a median of 12 children per age group (range 4-16 cases). Each age group represented a year of life. The distribution of cases inside every year or age group was also analysed. The analysis was done calculating the number of cases according to the month of birth inside each year. The distribution between years was not significantly different $(p=0.7891)$.

The inter- and intra-rater reliability was high (range ICC 0.8-0.99 Cronbach alpha 0.86-0.99).

\section{Covered femoral head volume (CFHV)}

A significant high correlation between mean CFHV and age was noted $(r=0.893 ; p<0.0001)$. CFHV increased from 


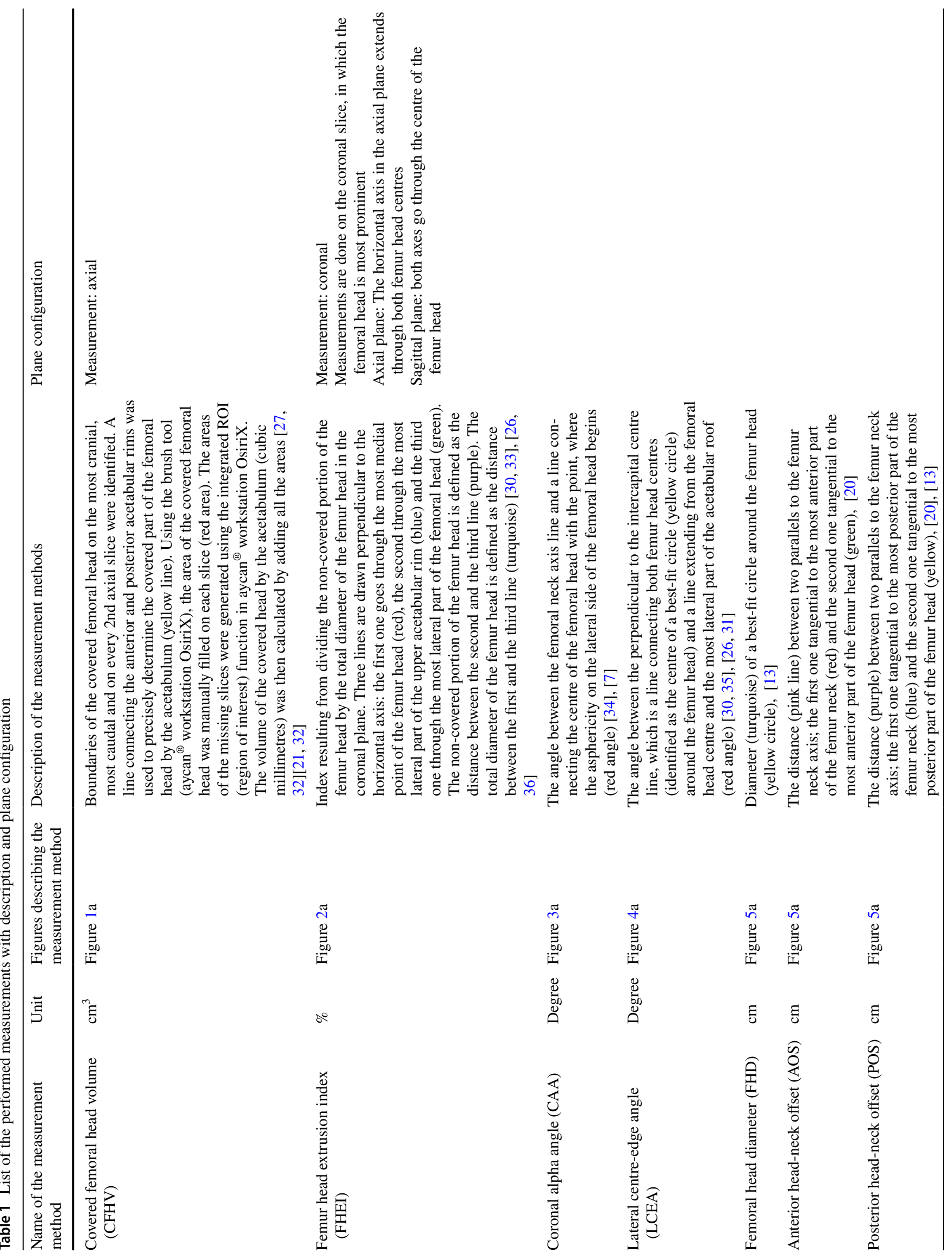




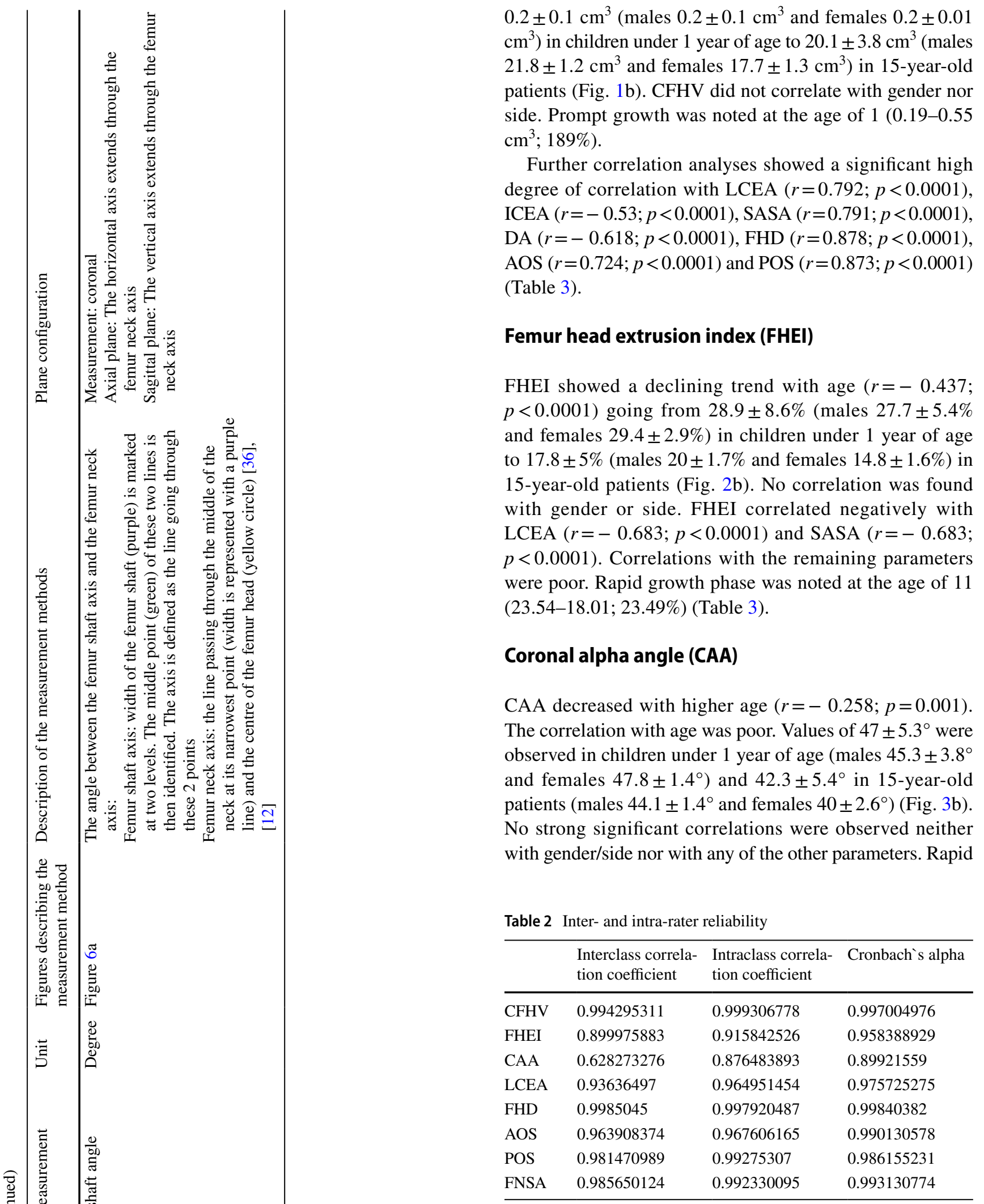

Covered femoral head volume (CFHV), femur head extrusion index (FHEI), coronal alpha angle (CAA), lateral center-edge angle (LCEA), femoral head diameter (FHD), anterior head-neck offset (AOS), posterior head-neck offset (POS), femoral neck-shaft angle (FNSA) 
Fig. 1 a Measurement method of covered femoral head volume (CFHV). *Red area: covered femoral head volume. b Results indicating the development of covered femoral head volume (CFHV) with age (colour figure online)

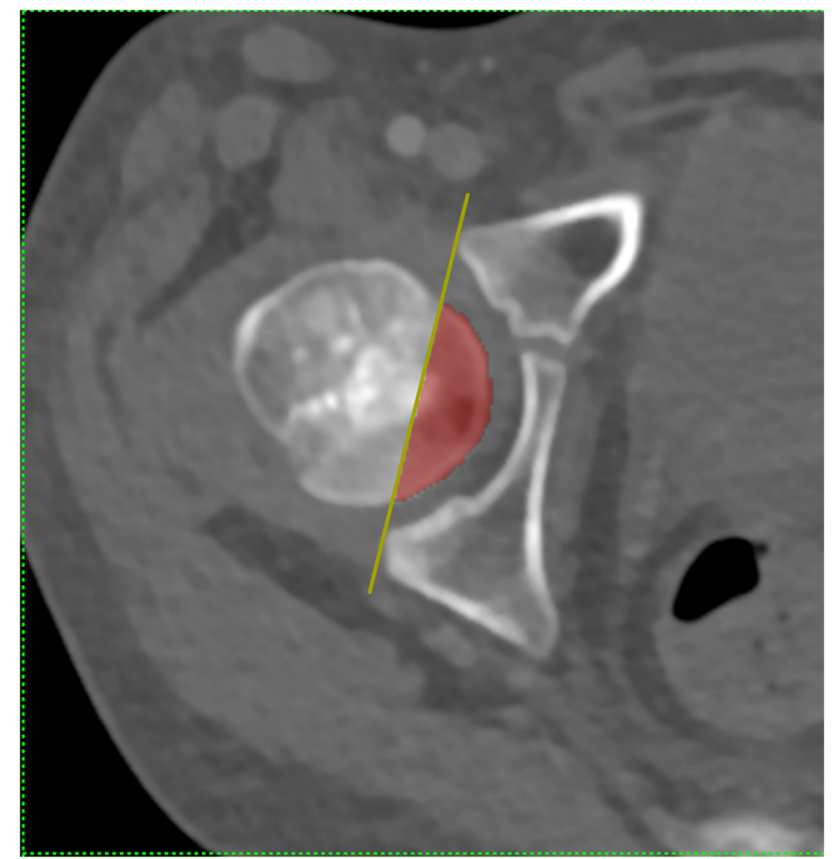

$\mathbf{a}$

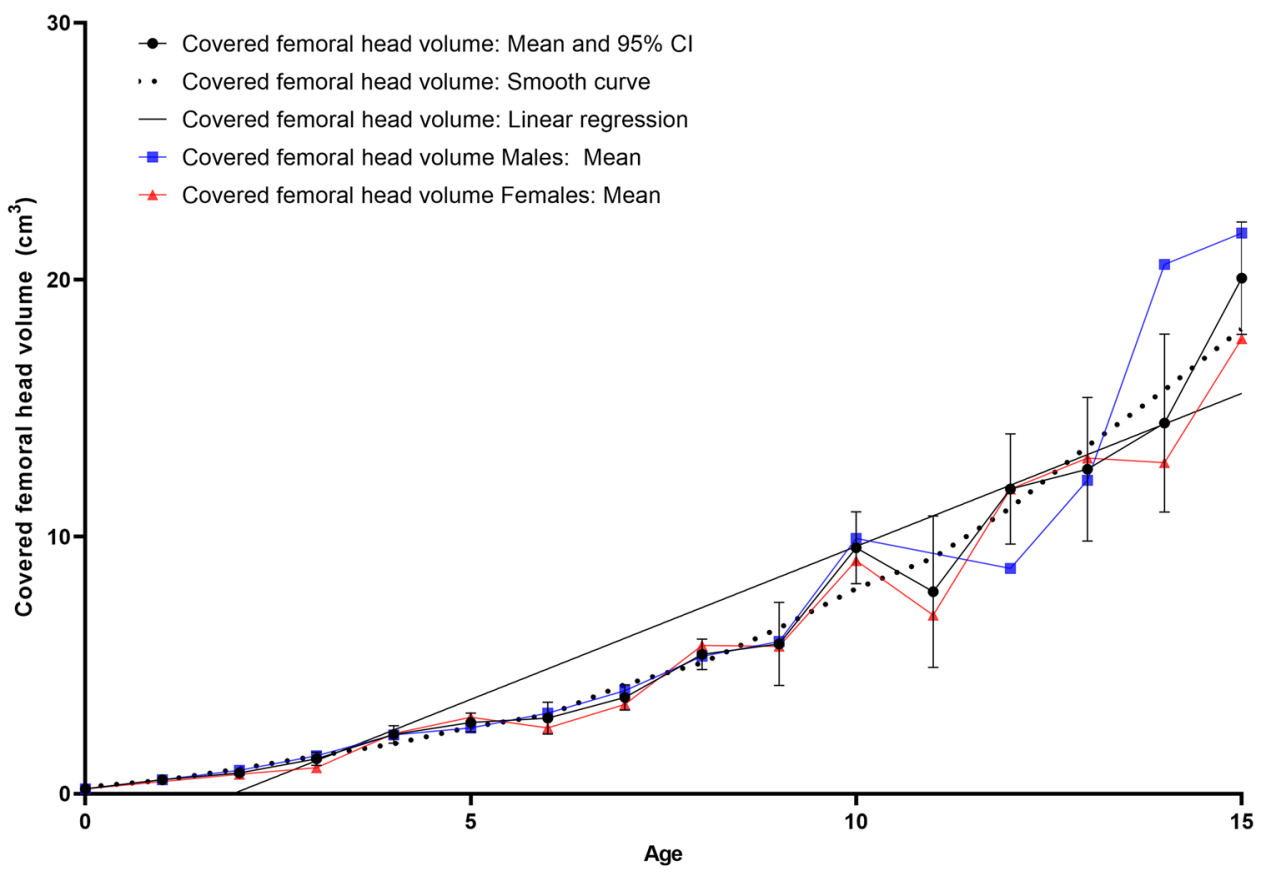

b growth phase was noted at the age of $1\left(51.69^{\circ}-47.43^{\circ}\right.$; $8.24 \%$ ) (Table 3).

\section{Lateral centre-edge angle (LCEA)}

The LCEA (Fig. 4b) increased with age $(r=0.716$; $p<0.0001)$. A strong significant correlation with gender or side was not found.
LCEA correlate significantly and strongly with CFHV $(r=0.792 ; p<0.0001)$ and FHEI $(r=-0.683 ; p<0.0001)$ as well as FHD $(r=0.643 ; p<0.0001)$, AOS $(r=0.603$; $p<0.0001)$ and POS $(r=0.645 ; p<0.0001)$. Fast growth phases were noted at the age of $1\left(15.72^{\circ}-20.28^{\circ} ; 29 \%\right)$ and $7\left(16.99^{\circ}-23.18^{\circ} ; 36.43 \%\right)$ (Table 3$)$. 
Table 3 Correlation analysis

\begin{tabular}{|c|c|c|c|c|c|c|c|c|c|c|c|}
\hline & Gender & Age & Side & CFHV & FHEI & CAA & LCEA & FHD & AOS & POS & FNSA \\
\hline \multicolumn{12}{|c|}{ CFHV } \\
\hline$r$ & 0.515 & $<0.0001$ & 0.917 & - & -0.495 & -0.341 & 0.792 & 0.878 & 0.724 & 0.873 & -0.418 \\
\hline$p$ & & & & - & $<0.0001$ & $<0.0001$ & $<0.0001$ & $<0.0001$ & $<0.0001$ & $<0.0001$ & $<0.0001$ \\
\hline \multicolumn{12}{|c|}{ FHEI } \\
\hline$r$ & 0.226 & $<0.0001$ & 0.525 & -0.495 & - & 0.187 & -0.683 & -0.384 & -0.379 & -0.35 & 0.134 \\
\hline$p$ & & & & $<0.0001$ & - & 0.015 & $<0.0001$ & $<0.0001$ & $<0.0001$ & $<0.0001$ & 0.082 \\
\hline \multicolumn{12}{|c|}{ CAA } \\
\hline$r$ & 0.899 & 0.001 & 0.515 & -0.341 & 0.187 & - & -0.243 & -0.268 & -0.259 & -0.256 & 0.287 \\
\hline$p$ & & & & $<0.0001$ & 0.015 & - & 0.001 & $<0.0001$ & 0.001 & 0.001 & $<0.0001$ \\
\hline \multicolumn{12}{|c|}{ LCEA } \\
\hline$r$ & 0.138 & $<0.0001$ & 0.609 & 0.792 & -0.683 & -0.243 & - & 0.643 & 0.603 & 0.645 & -0.235 \\
\hline$p$ & & & & $<0.0001$ & $<0.0001$ & 0.001 & - & $<0.0001$ & $<0.0001$ & $<0.0001$ & 0.002 \\
\hline \multicolumn{12}{|c|}{ FHD } \\
\hline$r$ & 0.627 & $<0.0001$ & 0.975 & 0.878 & -0.384 & -0.268 & 0.643 & - & 0.812 & 0.895 & -0.596 \\
\hline$p$ & & & & $<0.0001$ & $<0.0001$ & $<0.0001$ & $<0.0001$ & - & $<0.0001$ & $<0.0001$ & $<0.0001$ \\
\hline \multicolumn{12}{|c|}{ AOS } \\
\hline$r$ & 0.017 & $<0.0001$ & 0.711 & 0.724 & -0.379 & -0.259 & 0.603 & 0.812 & - & 0.704 & -0.447 \\
\hline$p$ & & & & $<0.0001$ & $<0.0001$ & 0.001 & $<0.0001$ & $<0.0001$ & - & $<0.0001$ & $<0.0001$ \\
\hline \multicolumn{12}{|c|}{ POS } \\
\hline$r$ & 0.156 & $<0.0001$ & 0.626 & 0.873 & -0.35 & -0.256 & 0.654 & 0.895 & 0.704 & - & -0.479 \\
\hline$p$ & & & & $<0.0001$ & $<0.0001$ & 0.001 & $<0.0001$ & $<0.0001$ & $<0.0001$ & - & $<0.0001$ \\
\hline \multicolumn{12}{|c|}{ FNSA } \\
\hline$r$ & 0.228 & $<0.0001$ & 0.981 & -0.418 & 0.134 & 0.287 & -0.235 & -0.596 & -0.447 & -0.479 & - \\
\hline$p$ & & & & $<0.0001$ & 0.082 & $<0.0001$ & 0.002 & $<0.0001$ & $<0.0001$ & $<0.0001$ & - \\
\hline
\end{tabular}

Covered femoral head volume (CFHV), femur head extrusion index (FHEI), coronal alpha angle (CAA), lateral center-edge angle (LCEA), femoral head diameter (FHD), anterior head-neck offset (AOS), posterior head-neck offset (POS), femoral neck-shaft angle (FNSA), Pearson coefficient $r$, statistical significance $p<0.00017$

\section{Femoral head diameter (FHD) and anterior/posterior head-neck offset (AOS/POS)}

FHD (Fig. 5b), AOS (Fig. 5c) and POS (Fig. 5d) increased with age. The correlation was strong and significant $(r=0.931 ; r=0.816$ and $r=0.899 ; p<0.0001)$. No correlation was found with gender or side.

FHD, AOS and POS correlated among each other as well as with CFHV $(r=0.878 ; r=0.724 ; r=0.873 ; p<0.0001)$, LCEA $(r=0.643 ; r=0.603 ; r=0.654 ; p<0.0001)$, SASA $(r=0.642 ; r=0.601 ; r=0.644 ; p<0.0001)$ and DA $(r=-0.711 ; r=-0.566 ; r=-0.651 ; p<0.0001)$. Fast growth phases were noted at the age of $1(1.44-1.82 \mathrm{~cm}$; $26.39 \%)$ for FHD and for AOS $(0.22-0.38 \mathrm{~cm} ; 72 \%)$. POS showed the fastest growth at the age of $7(0.47-0.7 \mathrm{~cm}$; $48.9 \%$ ) (Table 3).

\section{Femoral neck-shaft angle (FNSA)}

FNSA (Fig. 6b) angle showed a significant negative correlation with age $(r=-0.526 ; p<0.0001)$ and FHD $(r=-0.596 ; p<0.0001)$. No correlation with gender or side was found. Prompt growth phase was noted at the age of 1 $\left(156.85^{\circ}-147.4^{\circ} ; 6 \%\right)$ (Table 3).

Rapid growth phases were noted at the age of 1 for CFHV, CAA, LCEA, FHD, AOS and FNSA. A second growth phase was noted at the age of 7 with a prompt development of LCEA, and POS. A last growth phase was seen at the age of 11, where FHEI showed a marked increase.

A detailed list of the values of all measurements is to be found in Supplement proximal Femur.

\section{Discussion}

In order to detect morphological abnormalities of the proximal femur and femoral head, normal ranges of morphometric parameters of these structures have to be previously defined. These ranges vary widely with growth and are specific to each age group [5]. The importance of these ranges is that they help reduce the number of missed pathologies and their consequences. For instance, 
Fig. 2 a Measurement method of femur head extrusion index (FHEI). *Uncovered part of femoral head (purple) divided by femoral head diameter (turquoise). b Results indicating the development of femur head extrusion index (FHEI) with age (colour figure online)
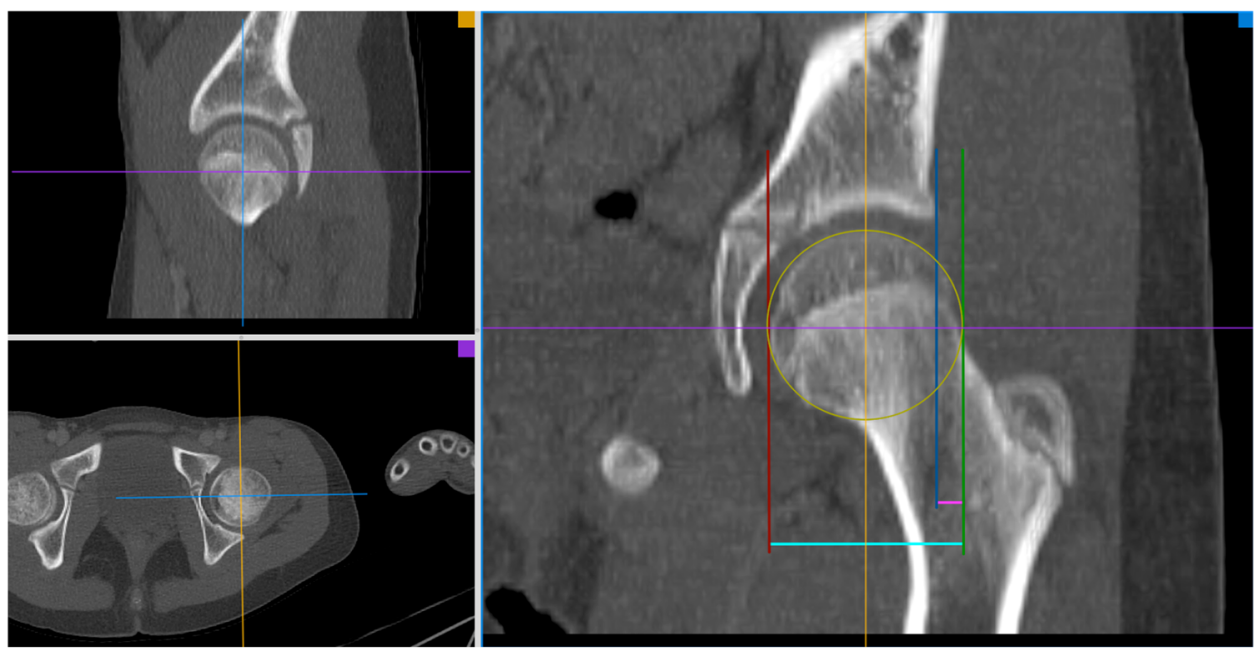

$\mathbf{a}$

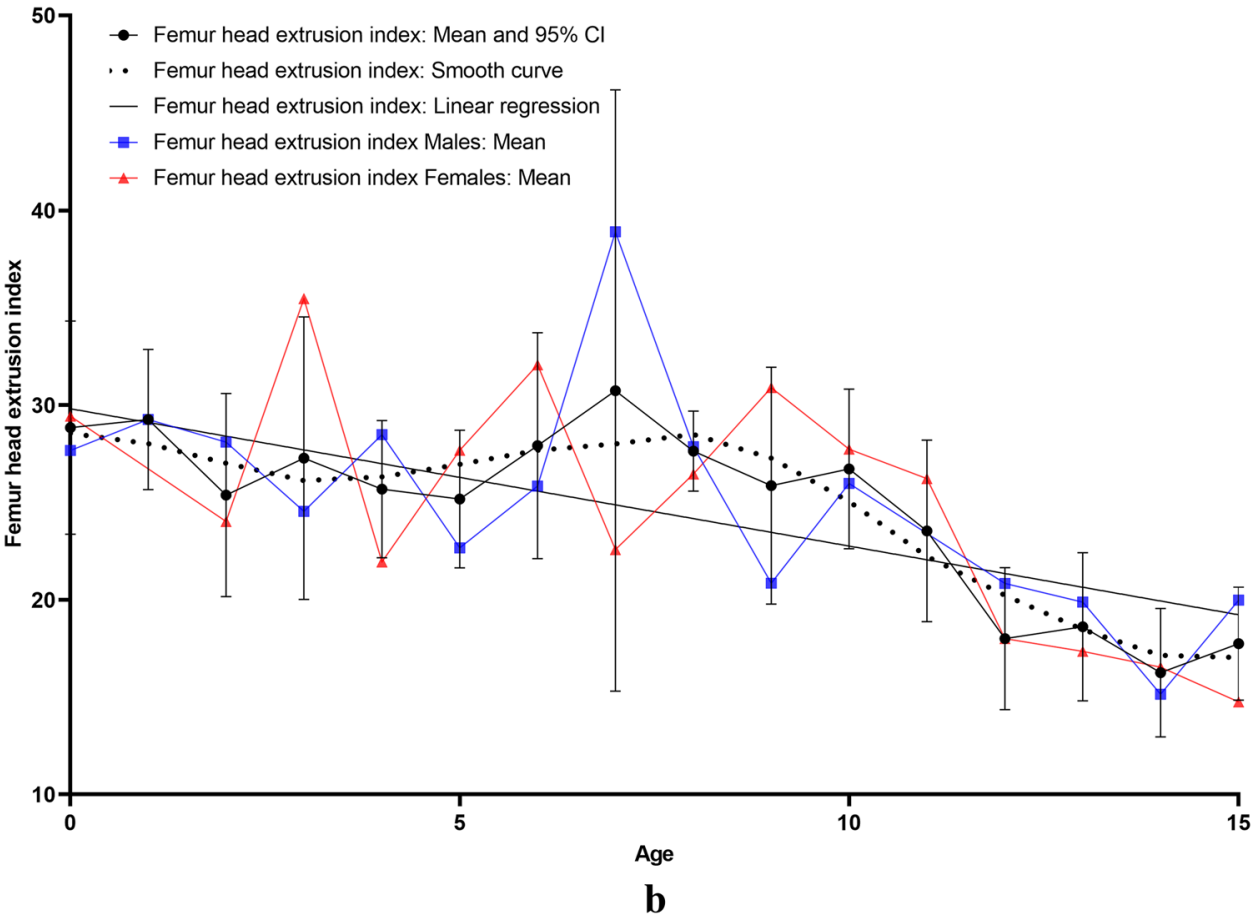

functional scoliosis, limb length difference and back pain as well as gait anomalies, decreased strength and degenerative hip pathologies are just few of the problems that can appear in late adolescence or young adulthood in cases of late diagnosis of DDH [28]. In such cases of late diagnosis and because of the possible treatment complications, untreated children may even have a better clinical outcome as those treated too late [28].

Another issue is the imaging technique to be chosen in the measurement of these parameters. Plain radiographs were long considered to be the method of choice in evaluating hip pathologies especially when it comes to hip dysplasia in children [6]. Other authors prefer computed tomography
(CT) scans because of their superior accuracy in comparison to conventional radiography [18].

However, even among skilled surgeons, all these twodimensional techniques were shown to be insufficiently reliable when it comes to evaluating the extent of the morphological deformities [10], especially when a patient's position during imaging varies like in cases of pelvis inclination or rotation or by deviation in the projection of the imaging technique [34]. Therefore, since almost all of the hip parameters depend on the pelvis position [6], many authors suggest 3D-CTs [19] to be the most precise technique in the measurement of such parameters, as it has been shown to be of superior accuracy compared to standard $\mathrm{CT}$ and plain 
Fig. 3 a Measurement method of coronal alpha angle (CAA). *Red angle: coronal alpha angle. b Results indicating the development of coronal alpha angle (CAA) with age (colour figure online)
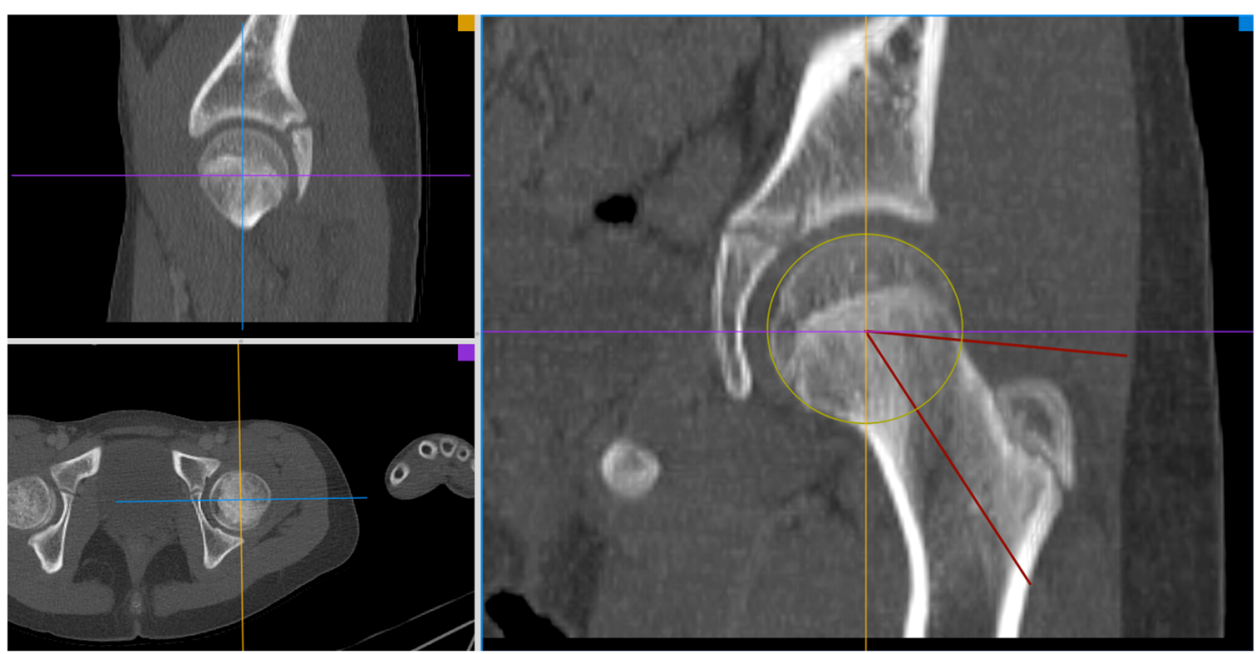

$\mathbf{a}$

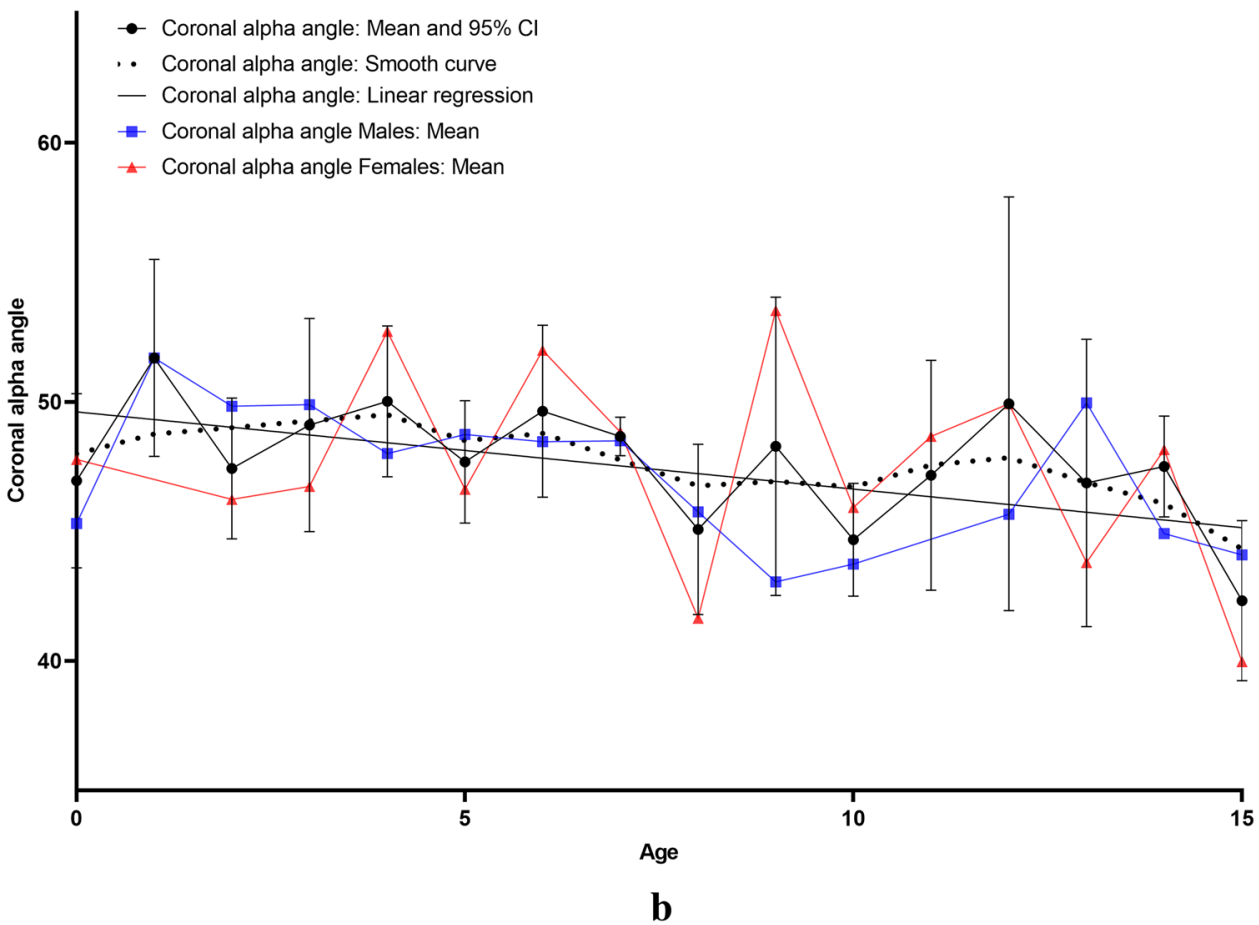

radiographs [14] as well as of superior inter- and intra-rater concordance compared to 2D-CT [11].

Therefore, aim of the current study was to deliver standardized normal reference values of the radiographic parameters classically used in the daily clinical practice to detect hip deformity especially hip dysplasia and to compare them with the reference values already reported in the literature. Literature values are usually X-ray-based. The presented values are based on inclination and rotation-corrected computed tomography scans at a broad age range to describe the complete anthropometric development of the paediatric proximal femur.
In the present study a total mean FHEI of $24.7 \pm 4.5 \%$ ( $\pm 1.1 \%$ standard error) was observed. The results correlate with the reference values for FHEI reported in the literature, where an FHEI of $>25 \%$ is considered as pathological [8, 23, 36]. Jandl et al. [9] measured the FHEI on the plain radiographs of 40 patients aged $5.8 \pm 2.3$ years $(2-11)$. All included patients had a unilateral Legg-Calvé-Perthes disease. The measurements were performed on the healthy contralateral side. The mean FHEI was markedly lower with $7 \pm 1.3 \%$ (standard error). Adjusting the ages of the patients of the current study to match those analysed in the 
Fig. 4 a Measurement method of lateral centre-edge angle (LCEA). *Red angle: lateral centre-edge angle. b Results indicating the development of lateral centre-edge angle (LCEA) with age. *Reference values: [29, 37] (colour figure online)
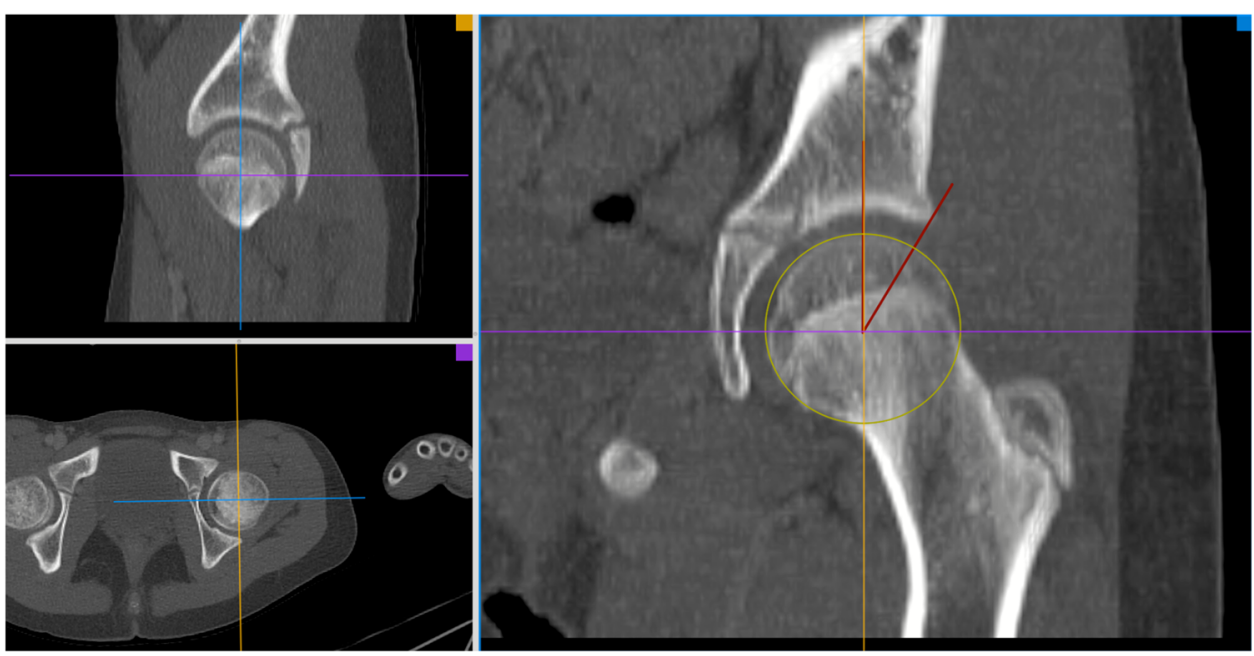

$\mathbf{a}$

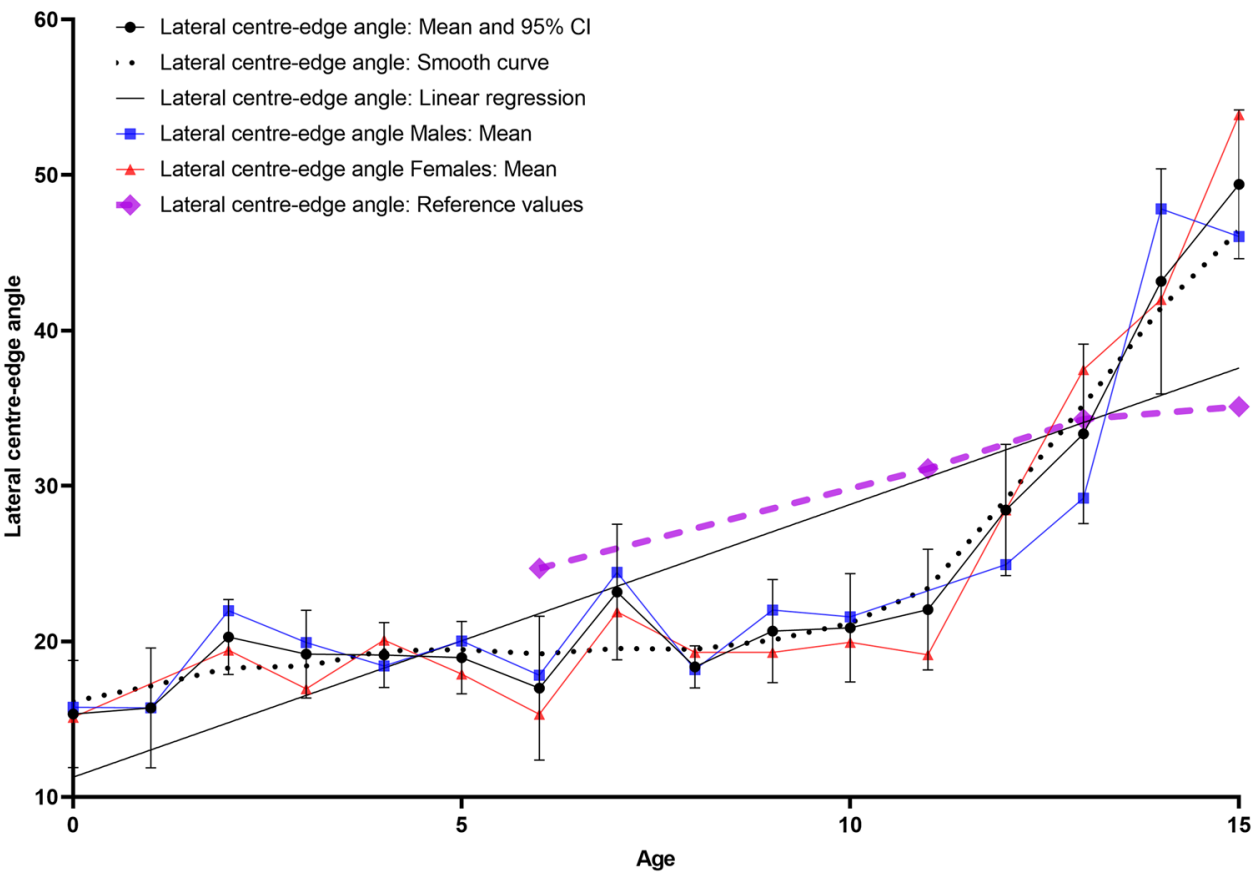

b publication of Jandl et al. [9] (2-11 years) would modify the mean FHEI to $26.6 \pm 2 \%$ ( \pm 0.6 standard error).

In the same study of Jandl et al. [9], the measurements were performed on the same 40 healthy hips using MRI scans. In comparison with the X-ray-based measurement an increase of the mean FHEI to $15 \pm 0.7 \%$ (standard error) was observed. This increase is due to the cartilaginous portions that could only be evaluated on MRI scans. The result was still slightly lower as the values measured in the current study.

A mean LCEA value of $24.1 \pm 9.9^{\circ}$ was measured in this study. The results are comparable with those of Novais et al. [22] where values of $26 \pm 5^{\circ}$ in the CT scans of asymptomatic adolescents aged 10-17 years were measured but lower than the values presented by Tönnis et al. [29], where a mean angle of $31.3 \pm 2.36^{\circ}$ was measured.

Tönnis et al. [29] further categorized his X-ray-based reference values and considered LCEA values of $>20^{\circ}$ for children aged $5-8$ years and $>25^{\circ}$ for children aged $\geq 9$ years to be a sign of sufficient femoral head coverage. In this study LCEA values of $19.4 \pm 2.7^{\circ}$ were measured in children $5-8$ years old and $31.1 \pm 11.5^{\circ}$ in children $\geq 9$ years old. The first values would have been considered marginally pathological according to the reference values of Tönnis et al. [29]. This suggests that the X-ray-based techniques may overestimate the actual values of these measurements. 
Fig. 5 a Measurement method of femoral head diameter (FHD) and anterior/posterior headneck offset (AOS/POS). *Turquoise: femoral head diameter. *Pink line: anterior head-neck offset. *Purple line: posterior head-neck offset. b Results indicating the development of femoral head diameter (FHD) with age. *Reference values: [35]. c Results indicating the development of anterior headneck offset (AOS) with age. d Results indicating the development of posterior head-neck offset (POS) with age (colour figure online)
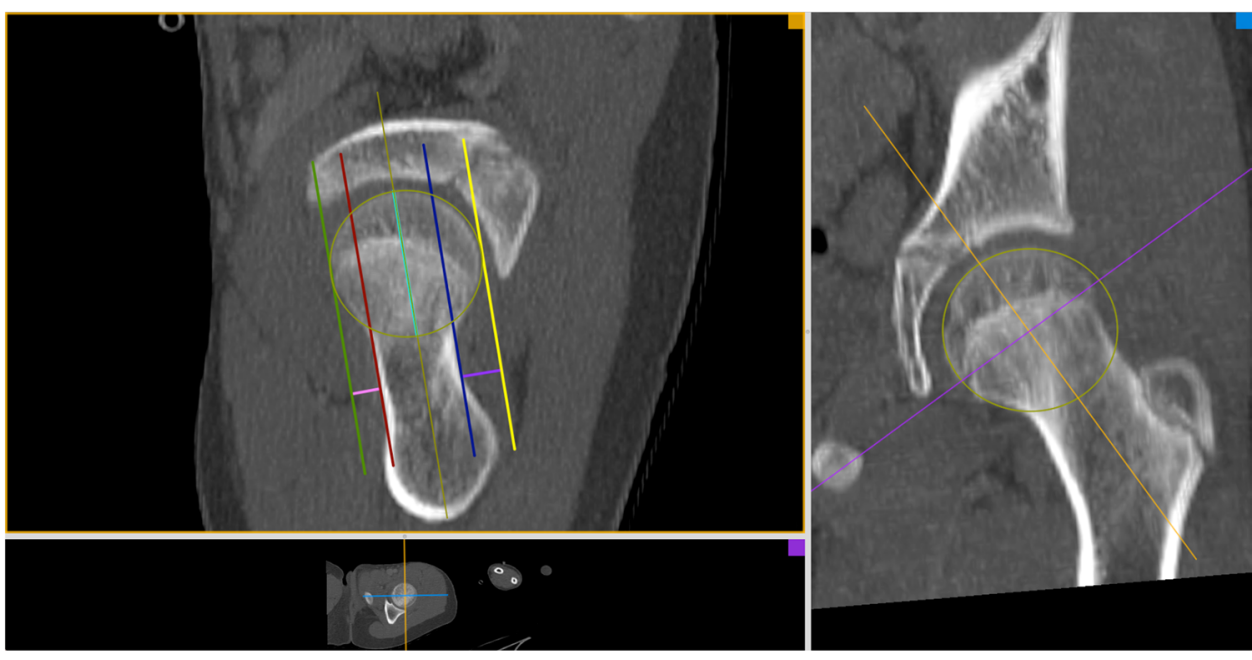

a

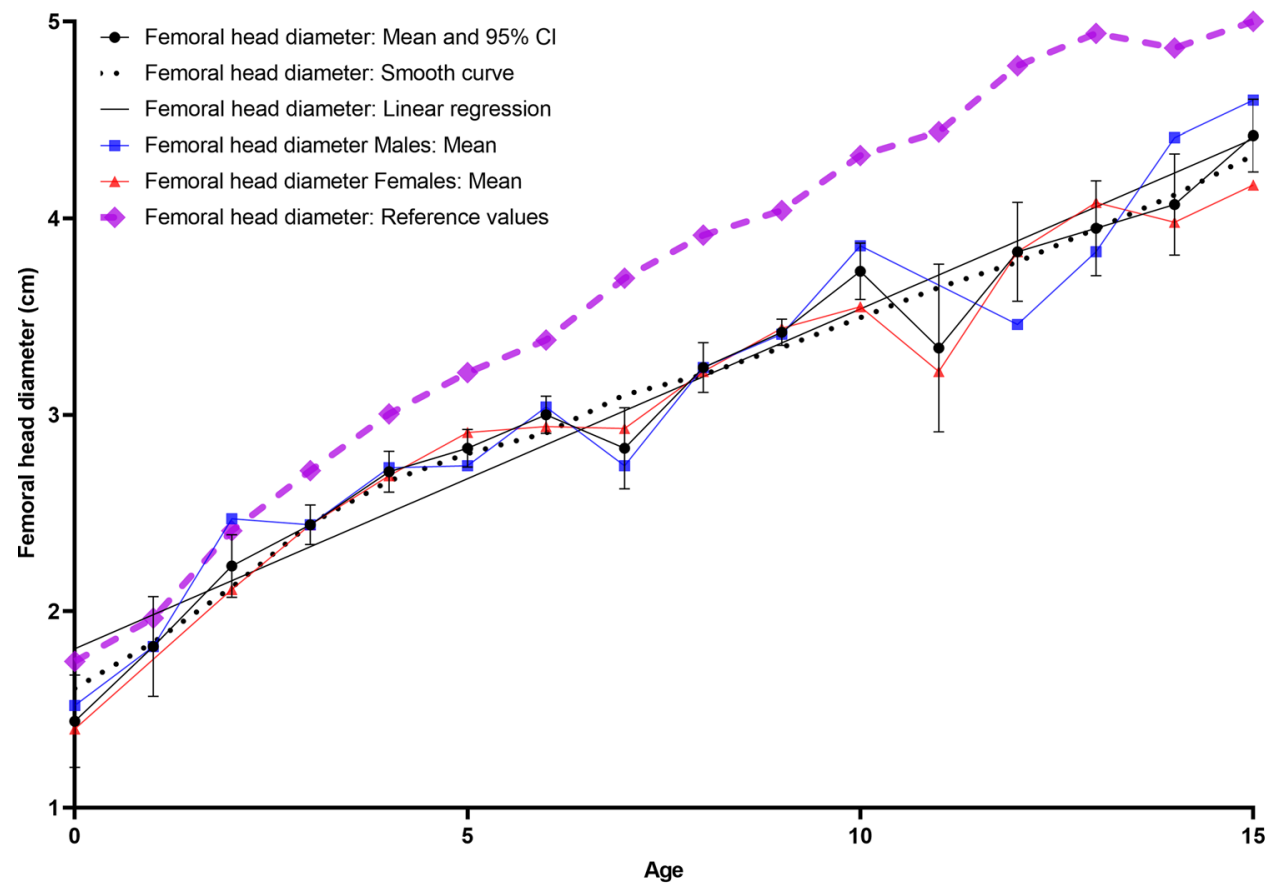

b
In the current study a mean FHD of $3.09 \pm 0.87 \mathrm{~cm}$ in males and $3.13 \pm 0.77 \mathrm{~cm}$ in females was measured. The values were slightly lower compared with those from the study of Wegener et al. [35]; here mean values of $3.74 \pm 1.18 \mathrm{~cm}$ were measured in the radiographs of 323 male children and $3.58 \pm 1.09 \mathrm{~cm}$ in 352 female children. All included children were under 16 years of age.

A total mean FNSA of $139.3 \pm 5.6^{\circ}$ was measured in this study. The values were slightly higher than the value $133 \pm 2.1^{\circ}$ presented by Tönnis et al. [29] but consistent with those from the study of Von Lantz et al. [33], where a mean FNSA of $136^{\circ}$ was observed. Von Lantz et al. [33] further presented values reflecting the chronological development of the hip (FNSA $144^{\circ}$ in children aged $1-3$ years, $135^{\circ}$ at $4-5$ years, $134^{\circ}$ at $9-13$ years and $130^{\circ}$ at $15-17$ years). These values were fairly comparable and in part slightly lower compared with the values measured in the current study (FNSA $145.3 \pm 8.9^{\circ}$ in children aged $1-3$ years, $140.8 \pm 0.2^{\circ}$ at $4-5$ years, $137.3 \pm 1.8^{\circ}$ at $9-13$ years and $136 \pm 1.9^{\circ}$ at 15 years).

It was not always possible to perform a direct comparison of our results with results in the literature. The limited publications found $[9,22,33,35]$ analyzed few or small age groups and included only some of the measurements. Jandl 
Fig. 5 (continued)

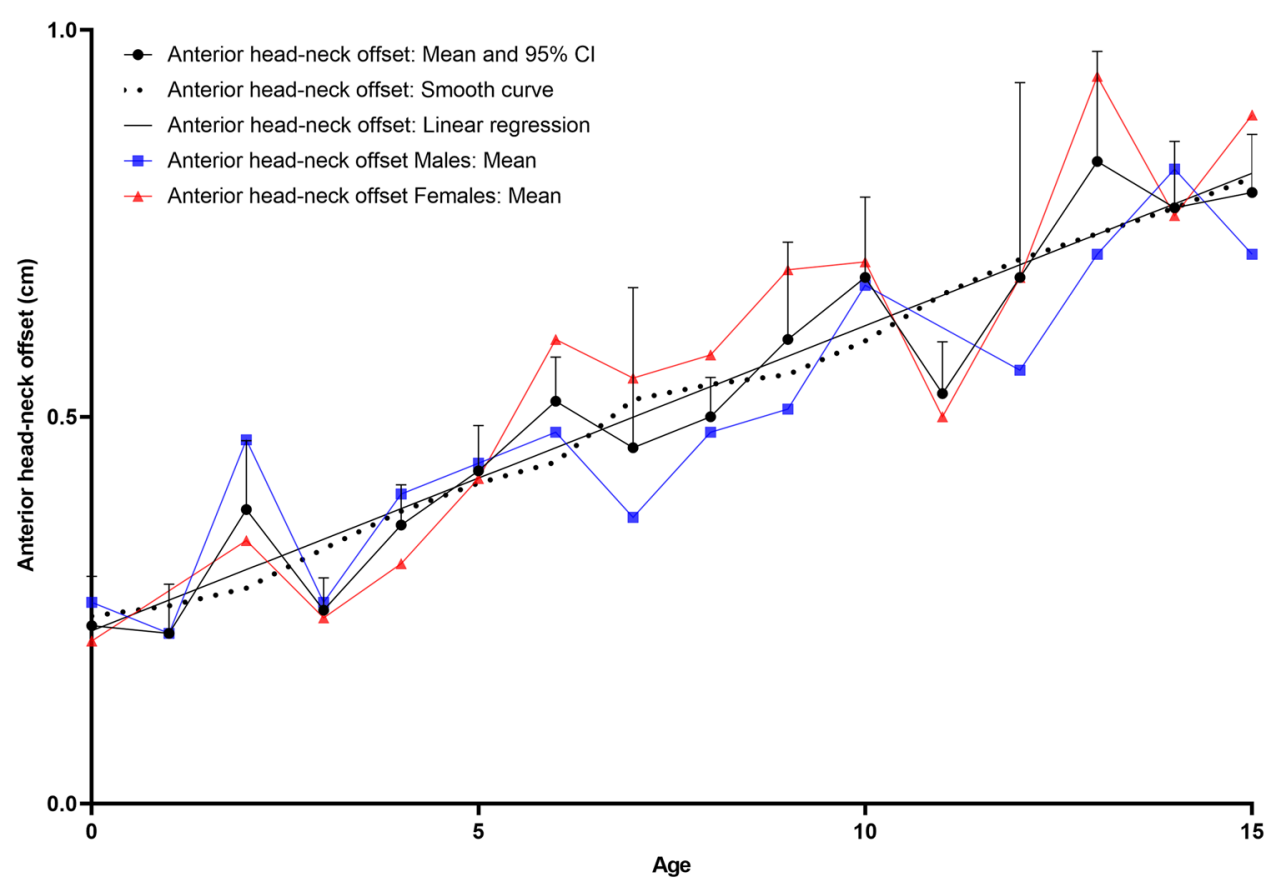

c

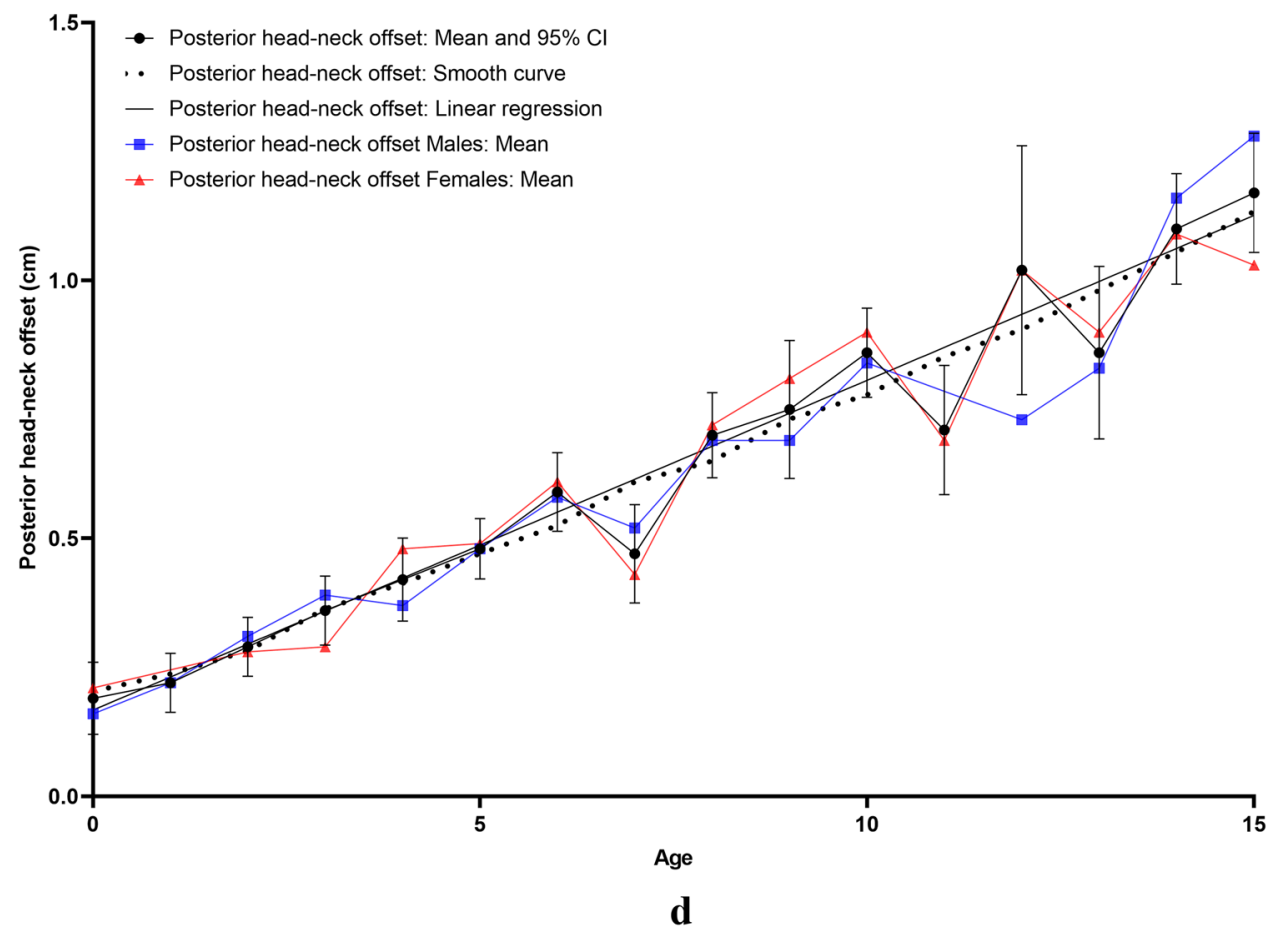

et al. [9] included 40 patients aged $5.8 \pm 2.3$ years $(2-11)$, Novais et al. [22] 27 patients aged $13 \pm 2$ years (10-17) and Wegener et al. [35] 675 patients aged 9 months to 16 years. These studies examined the above-mentioned parameters and, therefore, only these parameters were compared to our results. The remaining measurements (CFHV, CAA, AOS/POS) were not compared with literature data, since no analogous studies measuring them in multiple age groups were found.

Regarding growth pattern, the measured parameters showed rapid growth phases at the age of 1,7 and 11 . These results correlate with those reported by Wegener et al. [35], who investigated the development of joint space growth and observed rapid growth rates at the age of 1,8 and 12 . 
Fig. 6 a Measurement method of femoral neck-shaft angle (FNSA). *Red angle: femoral neck-shaft angle. b Results indicating the development of femoral neck-shaft angle (FNSA) with age. *Reference values: [29] (colour figure online)
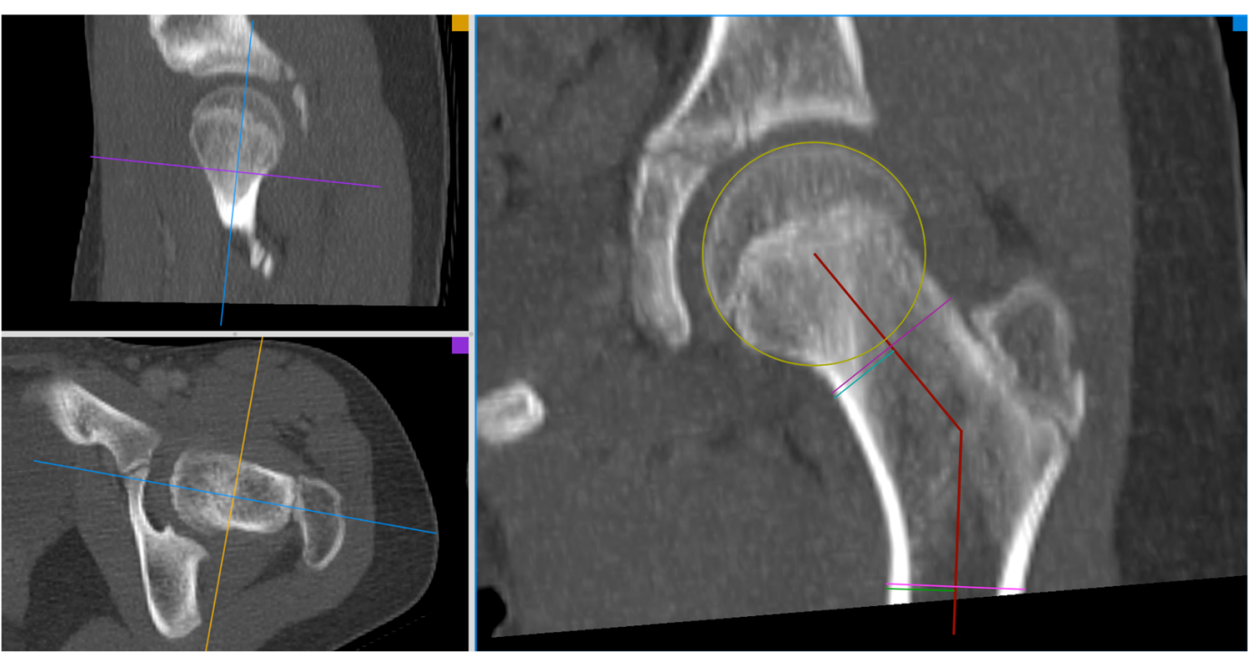

a

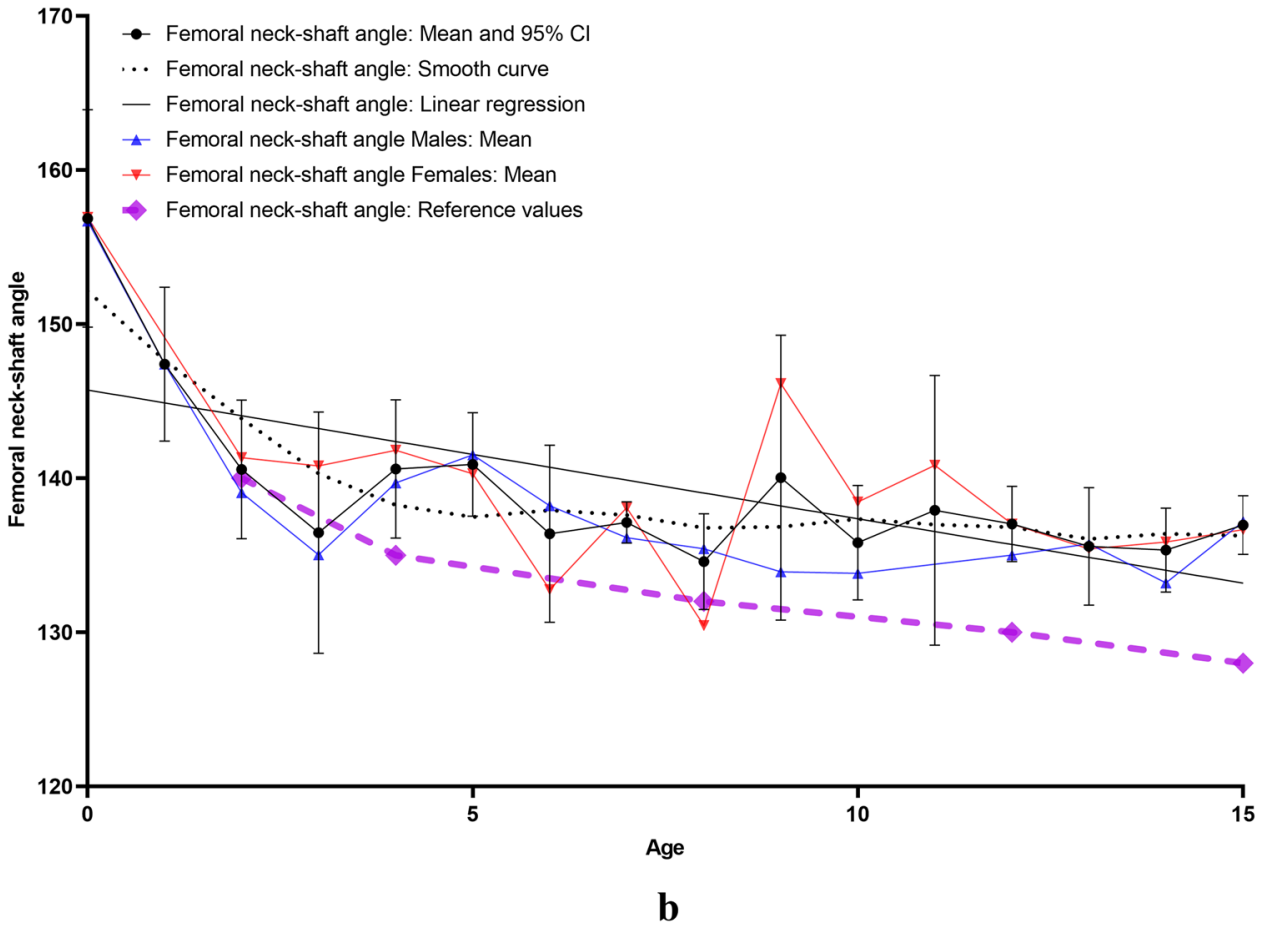

The included CT scans were performed for non-hip related reasons. This was not considered a limitation as the slice thickness in all analysed scans was of $1.5 \mathrm{~mm}$ or less, thus providing isotropic or nearly isotropic data that can be reconstructed after the imaging to any cutting plane.

One of the limitations of this study is the relatively small number of hips analysed in some age groups. The cases were also not distributed equally in all age groups, which may have made the charting of growth phases difficult. In addition, ethnicity was not recorded by the inclusion. In the metropolitan area where the study has been performed, the high ethnic variation could be considered as a limitation in the study.
The imaging techniques used for this study were performed in supine position. The absence of weight bearing while the CT scan is performed may have negatively affected the volumetric assessment of the covered femoral head [32].

Another limitation of the study is the underestimation of the cartilaginous structures in CT-based measurements. In order to avoid this, many authors suggest MRI-based techniques to address the inferiority of CT regarding evaluation of cartilaginous structures [22]. These techniques can provide a better assessment of cartilaginous parts; however, they showed many limitations. For instance, MRI techniques are not possible in patients with remaining metallic particles, due to artefact-related insufficient evaluation [2]. This 
problem is being currently addressed with the development of metal artefact suppression MRI sequences [27]. MRIbased measurements are also strongly affected by the variation in patients' position during the scan and compared with standard radiography, MRI-based measurements showed high level of discrepancy [26]. Modern MRI sequences offer high in-plane resolutions but are not by default isotropic, which makes the modification or angulation of the cutting planes after performance of the imaging not possible. Stelzeneder et al. [26] compared the anterior centre-edge angle in conventional radiographs and in MRI. The latter showed markedly higher angles up to $+28^{\circ}$ on both the sagittal and the oblique sagittal slices.

A last probable limitation may result from the fact that the patients included were not explicitly inspected for hip symptoms. All used CT scans were performed for non-hip-related reasons; however, it may indicate that the included cases may not represent a completely asymptomatic patient-collective.

At last, CT scans compared to MRI or plain radiography result in application of radiation or respectively higher radiation doses. This has to be taken into consideration, especially in young patients, as the stochastic risk of radiation-induced cancer or leukaemia development in this age group is higher. Thus, the importance of the correct CT indication, sticking to the A-L-A-R-A principle.

\section{Conclusions}

This wide-ranging quantitative analysis of the anthropometry of the proximal femur and femoral head in children/ adolescents under 15 years of age should be considered as a tool for paediatricians and orthopaedic/paediatric surgeons for early diagnosis of deformities in this area and provide guidance in the planning of possible operations.

Supplementary Information The online version contains supplementary material available at https://doi.org/10.1007/s00276-021-02841-3.

Funding Open Access funding enabled and organized by Projekt DEAL.

Open Access This article is licensed under a Creative Commons Attribution 4.0 International License, which permits use, sharing, adaptation, distribution and reproduction in any medium or format, as long as you give appropriate credit to the original author(s) and the source, provide a link to the Creative Commons licence, and indicate if changes were made. The images or other third party material in this article are included in the article's Creative Commons licence, unless indicated otherwise in a credit line to the material. If material is not included in the article's Creative Commons licence and your intended use is not permitted by statutory regulation or exceeds the permitted use, you will need to obtain permission directly from the copyright holder. To view a copy of this licence, visit http://creativecommons.org/licenses/by/4.0/.

\section{References}

1. Barbour KE, Helmick CG, Boring M, Brady TJ (2017) Vital signs: prevalence of doctor-diagnosed arthritis and arthritis-attributable activity limitation-United States, 2013-2015. MMWR Morb Mortal Wkly Rep 66:246-253. https://doi.org/10.15585/mmwr. mm6609e1

2. Beaulé PE, Allen DJ, Clohisy JC, Schoenecker PL, Leunig M (2009) The young adult with hip impingement: deciding on the optimal intervention. Instr Course Lect 58:213-222

3. Beck M, Kalhor M, Leunig M, Ganz R (2005) Hip morphology influences the pattern of damage to the acetabular cartilage: femoroacetabular impingement as a cause of early osteoarthritis of the hip. J Bone Jt Surg Br 87:1012-1018. https://doi.org/10.1302/ 0301-620x.87b7.15203

4. Boese CK, Dargel J, Oppermann J, Eysel P, Scheyerer MJ, Bredow J, Lechler P (2016) The femoral neck-shaft angle on plain radiographs: a systematic review. Skelet Radiol 45:19-28. https://doi. org/10.1007/s00256-015-2236-Z

5. Chiron P, Espié A, Reina N, Cavaignac E, Molinier F, Laffosse JM (2012) Surgery for femoroacetabular impingement using a minimally invasive anterolateral approach: analysis of 118 cases at 2.2-year follow-up. Orthop Traumatol Surg Res 98:30-38. https:// doi.org/10.1016/j.otsr.2011.08.011

6. Dandachli W, Ul Islam S, Richards R, Hall-Craggs M, Witt J (2013) The influence of pelvic tilt on acetabular orientation and cover: a three-dimensional computerised tomography analysis. Hip Int 23:87-92. https://doi.org/10.5301/hip.2013.10715

7. Gollwitzer H, Suren C, Strüwind C, Gottschling H, Schröder M, Gerdesmeyer L, Prodinger PM, Burgkart R (2018) The natural alpha angle of the femoral head-neck junction: a cross-sectional CT study in 1312 femurs. Bone Jt J 100-b:570-578. https://doi. org/10.1302/0301-620x.100b5.Bjj-2017-0249.R3

8. Jacobsen S, Sonne-Holm S, Søballe K, Gebuhr P, Lund B (2005) Hip dysplasia and osteoarthrosis: a survey of 4151 subjects from the Osteoarthrosis Substudy of the Copenhagen City Heart Study. Acta Orthop 76:149-158. https://doi.org/10.1080/0001647051 0030517

9. Jandl NM, Schmidt T, Schulz M, Rüther W, Stuecker MHF (2018) MRI and sonography in Legg-Calvé-Perthes disease: clinical relevance of containment and influence on treatment. J Child Orthop 12:472-479. https://doi.org/10.1302/1863-2548.12.180033

10. Larson CM, Moreau-Gaudry A, Kelly BT, Byrd JW, Tonetti J, Lavallee S, Chabanas L, Barrier G, Bedi A (2015) Are normal hips being labeled as pathologic? A CT-based method for defining normal acetabular coverage. Clin Orthop Relat Res 473:12471254. https://doi.org/10.1007/s11999-014-4055-2

11. Li LY, Zhang LJ, Zhao Q, Wang EB (2009) Measurement of acetabular anteversion in developmental dysplasia of the hip in children by two- and three-dimensional computed tomography. J Int Med Res 37:567-575. https://doi.org/10.1177/1473230009 03700234

12. Ma H, Han Y, Yang Q, Gong Y, Hao S, Li Y, Liu J (2014) Threedimensional computed tomography reconstruction measurements of acetabulum in Chinese adults. Anat Rec (Hoboken) 297:643649. https://doi.org/10.1002/ar.22885

13. Malhotra R, Kannan A, Kancherla R, Khatri D, Kumar V (2012) Femoral head-neck offset in the Indian population: a CT based study. Indian J Orthop 46:212-215. https://doi.org/10.4103/00195413.93681

14. Milone MT, Bedi A, Poultsides L, Magennis E, Byrd JW, Larson CM, Kelly BT (2013) Novel CT-based three-dimensional software improves the characterization of cam morphology. Clin Orthop Relat Res 471:2484-2491. https://doi.org/10.1007/ s11999-013-2809-x 
15. Mimura T, Mori K, Kitagawa M, Ueki M, Furuya Y, Kawasaki T, Imai S (2017) Multiplanar evaluation of radiological findings associated with acetabular dysplasia and investigation of its prevalence in an Asian population: a CT-based study. BMC Musculoskelet Disord 18:50. https://doi.org/10.1186/s12891-017-1426-3

16. Murphy SB, Ganz R, Müller ME (1995) The prognosis in untreated dysplasia of the hip. A study of radiographic factors that predict the outcome. J Bone Jt Surg Am 77:985-989. https:// doi.org/10.2106/00004623-199507000-00002

17. Murphy SB, Kijewski PK, Millis MB, Harless A (1990) Acetabular dysplasia in the adolescent and young adult. Clin Orthop Relat Res 261:214-223

18. Murphy SB, Simon SR, Kijewski PK, Wilkinson RH, Griscom NT (1987) Femoral anteversion. J Bone Jt Surg Am 69:1169-1176

19. Nakamura S, Yorikawa J, Otsuka K, Takeshita K, Harasawa A, Matsushita T (2000) Evaluation of acetabular dysplasia using a top view of the hip on three-dimensional CT. J Orthop Sci 5:533539. https://doi.org/10.1007/s007760070001

20. Nemtala F, Mardones RM, Tomic A (2010) Anterior and posterior femoral head-neck offset ratio in the cam impingement. Cartilage 1:238-241. https://doi.org/10.1177/1947603510363440

21. Novais EN, Bixby SD, Rennick J, Carry PM, Kim YJ, Millis MB (2014) Hip dysplasia is more severe in Charcot-Marie-Tooth disease than in developmental dysplasia of the hip. Clin Orthop Relat Res 472:665-673. https://doi.org/10.1007/s11999-013-3127-z

22. Novais EN, Ferrer MG, Williams KA, Bixby SD (2019) Acetabular retroversion and decreased posterior coverage are associated with sports-related posterior hip dislocation in adolescents. Clin Orthop Relat Res 477:1101-1108. https://doi.org/10.1097/corr. 0000000000000514

23. Pedersen DR, Lamb CA, Dolan LA, Ralston HM, Weinstein SL, Morcuende JA (2004) Radiographic measurements in developmental dysplasia of the hip: reliability and validity of a digitizing program. J Pediatr Orthop 24:156-160

24. Reijman M, Hazes JM, Pols HA, Koes BW, Bierma-Zeinstra SM (2005) Acetabular dysplasia predicts incident osteoarthritis of the hip: the Rotterdam study. Arthritis Rheum 52:787-793. https:// doi.org/10.1002/art.20886

25. Sarban S, Ozturk A, Tabur H, Isikan UE (2005) Anteversion of the acetabulum and femoral neck in early walking age patients with developmental dysplasia of the hip. J Pediatr Orthop B 14:410414. https://doi.org/10.1097/01202412-200511000-00003

26. Stelzeneder D, Hingsammer A, Bixby SD, Kim YJ (2013) Can radiographic morphometric parameters for the hip be assessed on MRI? Clin Orthop Relat Res 471:989-999. https://doi.org/10. 1007/s11999-012-2654-3

27. Talbot BS, Weinberg EP (2016) MR imaging with metal-suppression sequences for evaluation of total joint arthroplasty.
Radiographics 36:209-225. https://doi.org/10.1148/rg.20161 50075

28. Thomas SR (2015) A review of long-term outcomes for late presenting developmental hip dysplasia. Bone Jt J 97-b:729-733. https://doi.org/10.1302/0301-620x.97b6.35395

29. Tönnis D (1984) Die angeborene Hüftdysplasie und Hüftluxation im Kindes- und Erwachsenenalter, 1st edn. Springer, Berlin. https://doi.org/10.1007/978-3-662-06621-8

30. Vahlensieck M, Lang P, Chan WP, Grampp S, Genant HK (1992) Three-dimensional reconstruction. Eur Radiol 2:503-507. https:// doi.org/10.1007/BF00187541

31. Valera M, Ibáñez N, Sancho R, Llauger J, Gich I (2018) Acetabular overcoverage in the horizontal plane: an underdiagnosed trigger of early hip arthritis. A CT scan study in young adults. Arch Orthop Trauma Surg 138:73-82. https://doi.org/10.1007/ s00402-017-2811-y

32. van Bosse H, Wedge JH, Babyn P (2015) How are dysplastic hips different? A three-dimensional CT study. Clin Orthop Relat Res 473:1712-1723. https://doi.org/10.1007/s11999-014-4103-y

33. von Lanz T, Mayet A (1953) Die Gelenkkörper des menschlichen Hüftgelenkes in der progredienten Phase ihrer umwegigen Ausformung. Z Anat Entwicklungsgesch 117:317-345. https://doi.org/ 10.1007/BF00523625

34. Weber AE, Jacobson JA, Bedi A (2013) A review of imaging modalities for the hip. Curr Rev Musculoskelet Med 6:226-234. https://doi.org/10.1007/s12178-013-9174-y

35. Wegener V, Jorysz G, Arnoldi A, Utzschneider S, Wegener B, Jansson V, Heimkes B (2017) Normal radiological unossified hip joint space and femoral head size development during growth in 675 children and adolescents. Clin Anat 30:267-275. https://doi. org/10.1002/ca.22807

36. Welton KL, Jesse MK, Kraeutler MJ, Garabekyan T, Mei-Dan O (2018) The anteroposterior pelvic radiograph: acetabular and femoral measurements and relation to hip pathologies. J Bone Jt Surg Am 100:76-85. https://doi.org/10.2106/jbjs.17.00500

37. Wiberg G (1939) Studies on dysplastic acetabula and congenital subluxation of the hip joint with special reference to the complication of osteoarthritis. Acta Chir Scand 83(suppl 58):7-135

38. Zilber S, Lazennec JY, Gorin M, Saillant G (2004) Variations of caudal, central, and cranial acetabular anteversion according to the tilt of the pelvis. Surg Radiol Anat 26:462-465. https://doi. org/10.1007/s00276-004-0254-y

Publisher's Note Springer Nature remains neutral with regard to jurisdictional claims in published maps and institutional affiliations. 